\title{
Using of Remote Sensing and Aeromagnetic Data for Predicting Po- tential Areas of Hydrothermal Mineral Deposits in the Central East- ern Desert of Egypt
}

\author{
Mohamed Abdelkareem ${ }^{1}$, Abdelhady Akrby ${ }^{1}$, Mousa Fakhry ${ }^{1}$, Mohamed Mostafa ${ }^{2}$ \\ ${ }^{1}$ Geology Department, South Valley University, Qena 83523, Egypt \\ ${ }^{2}$ Egyptian Mineral Resources Authority, Cairo, Egypt
}

\begin{abstract}
This article explored mineral resources and their relation to structural settings in the Central Eastern Desert (CED) of Egypt. Integration of remote sensing (RS) with aeromagnetic (AMG) data was conducted to generate a mineral predictive map. Several image transformation and enhancement techniques were performed to Landsat Operational Land Imager (OLI) and Shuttle Radar Topography Mission (SRTM) data. Using band ratios and oriented principal component analysis (PCA) on OLI data allowed delineating hydrothermal alteration zones (HAZs) and highlighted structural discontinuity. Moreover, processing of the AMG using Standard Euler deconvolution and residual magnetic anomalies successfully revealed the subsurface structural features. Zones of hydrothermal alteration and surface/subsurface geologic structural density maps were combined through GIS technique. The results showed a mineral predictive map that ranked from very low to very high probability. Field validation allowed verifying the prepared map and revealed several mineralized sites including talc, talc-schist, gold mines and quartz veins associated with hematite. Overall, integration of RS and AMG data are powerful techniques in revealing areas of potential mineralization involved with hydrothermal processes.
\end{abstract}

Keywords: Remote Sensing; Aeromagnetic data; Hydrothermal alteration; Egypt

\section{Introduction}

Remote sensing technique commonly applied in reconnaissance studies. It represents an important way in deciphering several features such as geological, geomorphic, structural and mineral resources. NASA has launched several generations of unmanned Landsat satellites ( 1 to 8 ) that have acquired valuable RS data for mineral resources, structural features and land-use/cover information. Several studies used RS data for lithologic mapping (Sultan et al, 1986, Abdelsalam et al., 2000; Madani et al., 2003; Ramadan and Kontny, 2004; Abdelkareem and El-Baz, 2017; Ahmed et al., 2017; Abdelkareem et al., 2018), detecting HAZs (Sabins, 1997\& 1999; El Khidir and Babikir, 2013; Amuda et al., 2014;
Poormirzaee and Oskouei, 2010), and characterizing the geologic and the geomorphic features (Kamal El-Din and Abdelkareem 2018; Abdelkareem and El-Baz, 2015). Ratio images were performed for enhancing the spectral variations among the bands. This approach has been used in remote sensing to mark the spectral differences (Goetz et al., 1983), to map lithology and HAZs (e.g. Segal, 1983). This is because such transformation process can display a high contrast range of spectral characteristics than do individual bands.

Aeromagnetic data represent a significant factor in identifying subsurface structures based on the variation of the geomagnetic field, which results from the differences in the magnetite content of the associated rock

Copyright (C) 2018 Mohamed Abdelkareem et al.

doi: $10.18282 /$ rs.v7i1.112

This is an open-access article distributed under the terms of the Creative Commons Attribution Unported License

(http://creativecommons.org/licenses/by-nc/4.0/), which permits unrestricted use, distribution, and reproduction in any medium, provided the original work is properly cited. 
units. Such geologic structures represented the conduit of the mineral deposits associated with hydrothermal solutions. Therefore, inte-gration of RS images and AMG data would complement the surface and subsurface view of the present study, where we can understand the surface/subsurface geologic structures, characterize the lithologic features, and highlight the probable areas of mineralization.

Several studies were conducted in the Central Eastern Desert (CED) of Egypt using RS data (e.g., El-Etr et al., 1979; O'Connor and McDonald, 1988; Sultan et al, 1988; El-Rakaiby, 1995; Farghaly, 1999; Gad and Kusky, 2006; Sultan et al. 1988). Landsat data were utilized for lithologic mapping and mineral exploration in arid regions (e.g., Sultan et al, 1986 \& 1987; Sabins, 1997; Abdelsalam et al., 2000; Madani et al., 2003; Ramadan and Kontny, 2004). O'Connor and McDonald (1988) used Landsat Thematic Mapper (TM) and applied color composite of band ratios 5/7, 5/1 and 4 in R, G, and B, respectively, to distinguish volcanic, serpentinite-mélange and late to post-tectonic molasse sedimentary units in the Central Eastern Desert of Egypt. Sultan et al. (1988) integrated field and observations of Landsat data in the CED and revealed elongated NW-SE deformation associated with faulting and ductile shear zones, NW trending related to left-lateral faults, and some lithologic contacts related to faulting. They related these features to the Najd fault systems and were not the results of obduction/accretion tectonics.

The main aim of the present study is to explore the optimum area of mineral resources based on combining surface/subsurface structural elements and zones of hydrothermal processes. So as to accomplish this objective the HAZs and areas of structural complexity will be delineated using SRTM, OLI and aeromagnetic data. Field and metalogenic data will validate the mineral predictive map.

\section{Study area}

The study area is situated in the eastern part of the CED of Egypt, extending between Longitudes $33^{\circ} 52^{\prime} 50^{\prime \prime}$ $\mathrm{E}$ and $34^{\circ} 15^{\prime} 00^{\prime \prime} \mathrm{E}$, and Latitudes $25^{\circ} 54^{\prime} 00^{\prime \prime} \mathrm{N}$ and $26^{\circ}$ $15^{\prime} 00^{\prime \prime} \mathrm{N}$. It occupies about $11980 \mathrm{sq} \mathrm{km}$. It represents an important part of the proposed "Golden Triangle" project area that extending in the CED of Egypt, between Qena, Safaga and Quseir (Figure 1). It occupies the area west of the Quseir city in the Red Sea that well known by G. Duwi (Quseir) area (Figure 1). Lithologically, the exposed rock units in the study area vary from Precambrian to Recent. The Precambrian rock units are represented by igneous and metamorphic rocks. The eastern part of the basement exposure is overlain by younger sedimentary formation ranging in age from late Mesozoic to Quaternary.

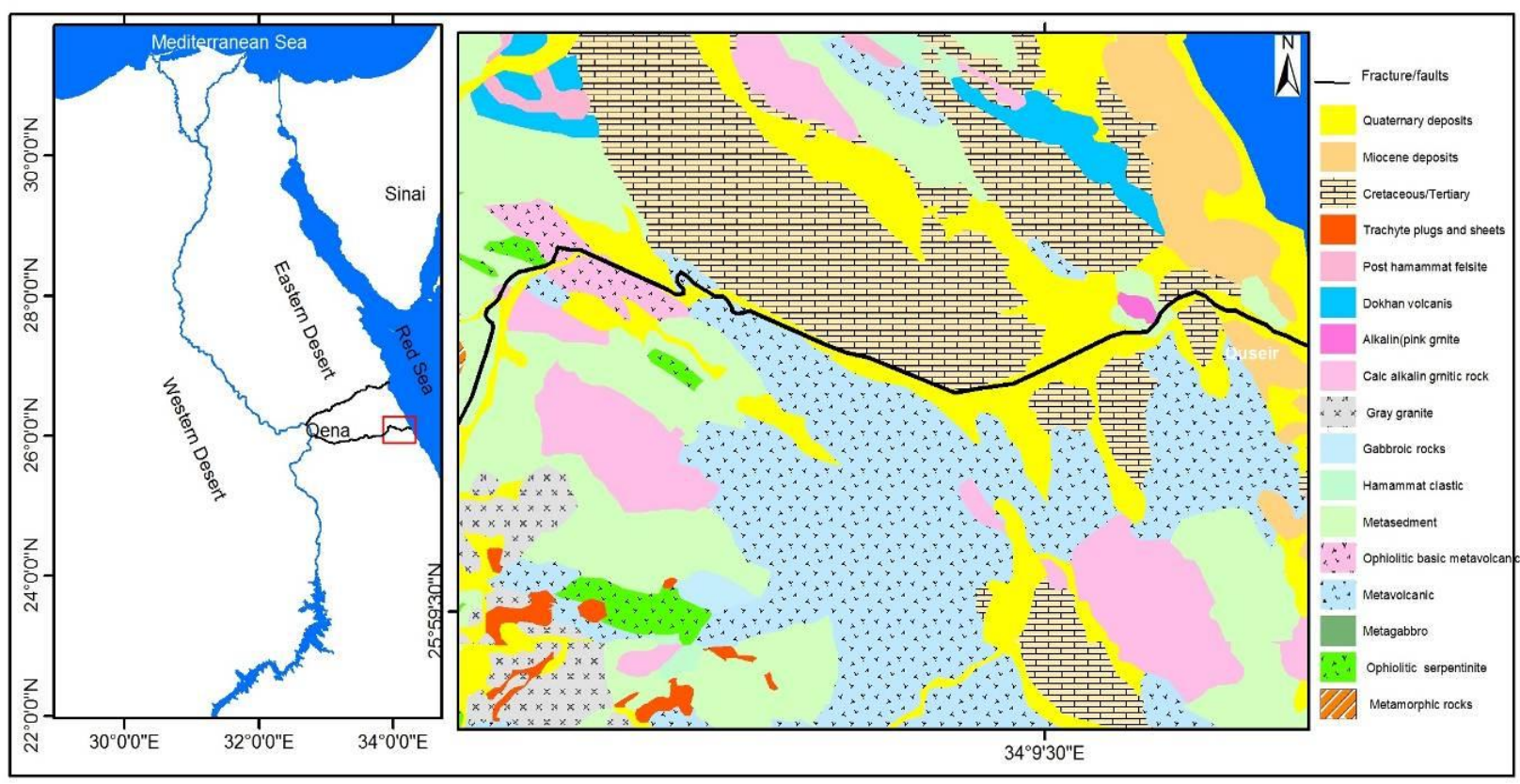

Figure 1. (a) Location map of the study area marked in red polygon nearness to the Red Sea zone. (b) Landsat ETM+ mosaic image showing the locality of the study area west of Quseir city and the accessible roads from Nile Valley to the Red Sea; (c) Geologic map of study (modified after Conoco, 1987). 
The study area occupied by Precambrian basement complex and Phanerozoic sedimentary rocks (Said, 1962 \& 1990). The basement complex, considered a part of the ANS (Fig. 2.1) which formed contemporaneously with the Late Proterozoic to Early Paleozoic time. During the Tertiary, the Arabian-Nubian Shield (ANS) was rifted apart by the Red Sea. The ANS of northeast Africa was cratonized during the late Pan-African Orogeny due to the collision of East and West Gondwana (Ghebreab, 1998). The basement complex in the ED of Egypt built up of island-arc/back-arc systems, consisting of metavolcanic, metasediments and associated ophiolitic rock assemblages (Gass, 1977, Kröner, 1985). These assemblages then, deformed and intruded by granitic masses of Syn- Late- and Post-tectonic during the Pan-African Orogeny.

\section{Data used and methods}

The available datasets such as a geological map, airborne total magnetic field survey, remote sensing, and field data were integrated in the present study using different spatial analysis techniques. There are several studies were conducted to integrate aeromagnetic and RS data integration (e.g., Rigol-Sanchez et al., 2003; Alexander et al., 2015; Abdelkareem et al., 2018). These studies have successfully displayed approaches to link the occurrence of mineral resources and understanding the surface and subsurface features.

\subsection{Remote sensing data}

In this article we utilized OLI data was launched on February 11, 2013 from Vandenberg Air Force Base in California. OLI presents data from nine spectral bands (visible, near and shortwave infrared bands and two thermal long-wave bands). One image (path 174, raw 42) of Landsat data that acquired from USGS was processed using ENVI and ArcGIS software packages to extract the lithologic and HAZs.

Image transformation approaches like band ratios and PCA were utilized. In band ratios, dividing process of the digital numbers (DNs) of two spatially consistent bands are applied (Edgardo et al., 1992; Cappaccioni et al., 2003; Abdelkareem and El-Baz 2017). This technique clearly highlights the spectral variations of the mapped materials. Moreover, the PCA technique was performed. The statistical parameters are computed to characterize which component is significant based on the eigenvectors values to delineate the plausible area of hydrothermal alteration.

\subsection{Aeromagnetic data}

The utilize AMG data were compiled from the surveys that have been conducted in 1984 by the Western Geophysical Company of America (Aero Service Division), the Egyptian General Petroleum Corporation (EGPC) in conjunction with the Egyptian Geological Survey and Mining Authority (EGSMA).

The Aeromagnetic magnetic anomaly (TMI) data was processed to be reduced to the pole (RTP). This technique was done by subtracting the International Geomagnetic Reference Field (IGRF) (Figure 2b). The residual and Euler methods also were applied. Euler deconvolution technique applies potential field derivatives to reveal subsurface depth of a magnetic or gravity source (Hsu, 2002). It represents a valuable method for delineating contacts and depth estimation. The eminence of depth estimation depends on the selection of the structural index (SI) value and appropriate sampling of the data. It has become a tool to determine the source location of the potential field anomalies (Thompson, 1982; Reid et al., 1990), and provides automatic estimates of source location and depth. To conduct this, the SI was applied to characterize many source types. The SI can be interpreted as the exponent in a power law expressing the decreasing of field strength versus distance from the source.

\section{Results and discussion}

\subsection{Optical remote Sensing data}

Utilizing Landsat data allowed highlighting areas of hydrothermal alteration. This was based on the spectral signatures of the rock units. Utilizing band ratio composites 6/7, 6/5, 5 in R, G, and B, (Ramadan et al., 2001; Ramadan and Sultan, 2004) highlighted areas of HAZs that marked in yellow and pinkish colors (Figure 3a, Figure 3b).

The PCA of selected bands is applied in the selected study area. Selected bands of 2, 4, 5, and 6 of OLI sensor were developed to show iron oxide image (Table 1). The results showed that the eigenvalue represents $96.64 \%$ of total variance and the first component PC1 represents a positive loading from all bands. The PC4 displays positive loading from band 2 (0.70) versus band $4(-0.66)$. Therefore, the PC4 was negated to display the iron-rich 
minerals in bright pixels.

In order to highlight areas of $\mathrm{OH}$-bearing minerals, bands of 2, 5, 6, and 7 of Landsat-8 (image H) were used (El Khidir and Babikir, 2013; Eldosouky, 2017). The results displayed that $\mathrm{PC} 3$, there is a contrast between eigenvector loading from band 6 (-0.66) and band 7 (0.59). Therefore, the darkest pixels represent the OH-bearing minerals. After negation of the PC3, the hydrothermal altered areas appear in bright tone.

In order to generate Crosta's alteration image (Figure 3c), the $\mathrm{F}, \mathrm{H}+\mathrm{F}, \mathrm{H}$ images are displayed in $\mathrm{R}, \mathrm{G}$, and

The extent of alteration zones is considered here for exploring areas of mineral resources which connected to hydrothermal activities. The Landsat data allowed highlighting the HAZs (Figure 3g). Combining data from band ratios and PCA well defined the rock alteration resulting from the hydrothermal activities. These zones can distinguish areas rich in hydroxyl and iron-oxide alterations. Therefore, this image was graded into five ranks after assigning weight factor for each class. The higher weight (numeric number) represents a higher grade of mineral favorability (Figure 3g).

\section{2 Radar remote sensing for lin- eament extraction}

Analysis of SRTM DEM (Fig. 4a) revealed that the variations in topography range from 0 to $876 \mathrm{~m}$ (a.s.1). Moreover, it provided information on the geometry that was not identifiable by other RS techniques. The most elevated areas encountered in G. Duwi (elongated ridge trends NW-SE; $550 \mathrm{~m})$, G. Hamrawein ( 650), G.
$\mathrm{B}$, respectively. This showed the suggested alteration zones in brighter whitish-yellowish hues. Higher DN defines the optimum areas of the alteration zones. The resulted map was classified into many classes depending on the grade of the alteration Undesirable similar hues resulted from the sediments are masked by white polygon. Noteworthy, displaying band ratio $6 / 7$ also highlighted the $\mathrm{OH}$-bearing minerals (Figure 3e, Figure 3f) much more similar to Crosta technique. Accordingly, the HAZs are clearly highlighted in bright tone that graded into five zones (Figure 3f).

Umm Himeiyir ( 580m), G. Murr $(\sim 715 \mathrm{~m})$, and G. Umm Shagir ( $\sim 600 \mathrm{~m})$. The geological interpretation of the Landsat imagery and SRTM data (Figure 4a) revealed structural discontinuity that represent in lineaments. The results of lineaments analysis including density map (Fig. 4d) and the distribution of lineaments using rose diagram reveal that the basement rocks (e.g. granites, metavolcanics, metasediments) and Cretacious/Tertiary sedimentary succession in the investigated area are highly fractured. While the area of sedimentary rocks displays less density. The lineaments density map also reveals discontinuous distribution on the area which revealing a major tectonics. Plotting lineaments on Rose diagram of Rock ware software packages (Figure 4c) reveals that the study areas are dominated by trends of $\mathrm{N}$ $30^{\circ} \mathrm{W}$, and $\mathrm{N} 40^{\circ} \mathrm{W}, \mathrm{N} 35^{\circ} \mathrm{E}, \mathrm{N} 45^{\circ} \mathrm{E}$; however, the $\mathrm{N}-\mathrm{S}$ and $\mathrm{E}-\mathrm{W}$ respectively, according to decreasing of abundance. The NW-SE lineaments have longer and abundant in number than the NE-SW, N-S, and E-W trends.

\begin{tabular}{|l|l|l|l|l|l|}
\hline Eigenvector & Band 2 & Band 4 & Band 5 & Band 6 & Eignvalue \% \\
\hline PC1 & 0.15022 & 0.441575 & 0.609239 & 0.641306 & 96.64965 \\
\hline PC2 & 0.221567 & 0.369174 & 0.481423 & -0.763447 & 2.71183 \\
\hline PC3 & 0.660352 & 0.479502 & -0.574698 & 0.061116 & 0.517105 \\
\hline PC4 & 0.701624 & -0.66242 & 0.258423 & 0.046263 & 0.121419 \\
\hline
\end{tabular}

Table 1. PCA of selected bands 2, 4, 5 and 6

\begin{tabular}{|l|l|l|l|l|l|}
\hline Eigenvector & Band 2 & Band 5 & Band 6 & Band 7 & Eigenvalue \% \\
\hline PC1 & -0.120062 & -0.49843 & -0.67361 & -0.53236 & 97.5627 \\
\hline PC2 & -0.2805 & -0.75513 & 0.157252 & 0.571283 & 1.627296 \\
\hline PC3 & 0.425616 & 0.155359 & -0.66236 & 0.596655 & 0.616379 \\
\hline PC4 & 0.851913 & -0.3965 & 0.287758 & -0.18502 & 0.193578 \\
\hline
\end{tabular}

Table 2. PCA of selected bands 2, 5, 6 and 7. 

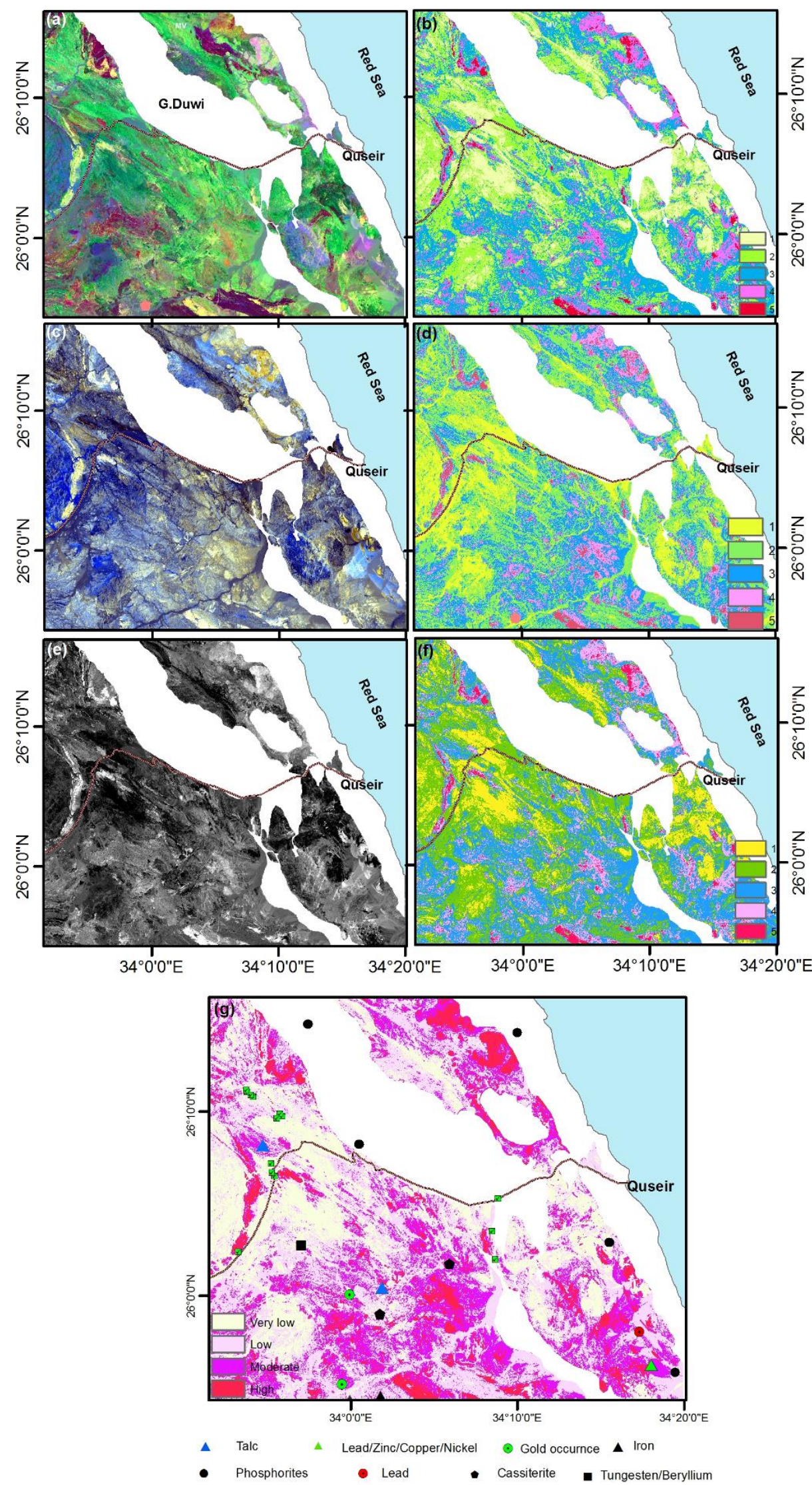

Figure 3. Alteration zones (a) band ratio 6/7, 6/5, 5; (b) classified band ratios of Ramadan et al. (2004); (c) Crosta technique, F, $\mathrm{H}+\mathrm{F}, \mathrm{H}$ in R, G, and B ; (d) classified Crosta technique; (e) Band ratios 6/7; (f) classified band ratios 6/7(alteration zones compiled from band ratios and PCA.; (g) alteration zone map of the study area. 

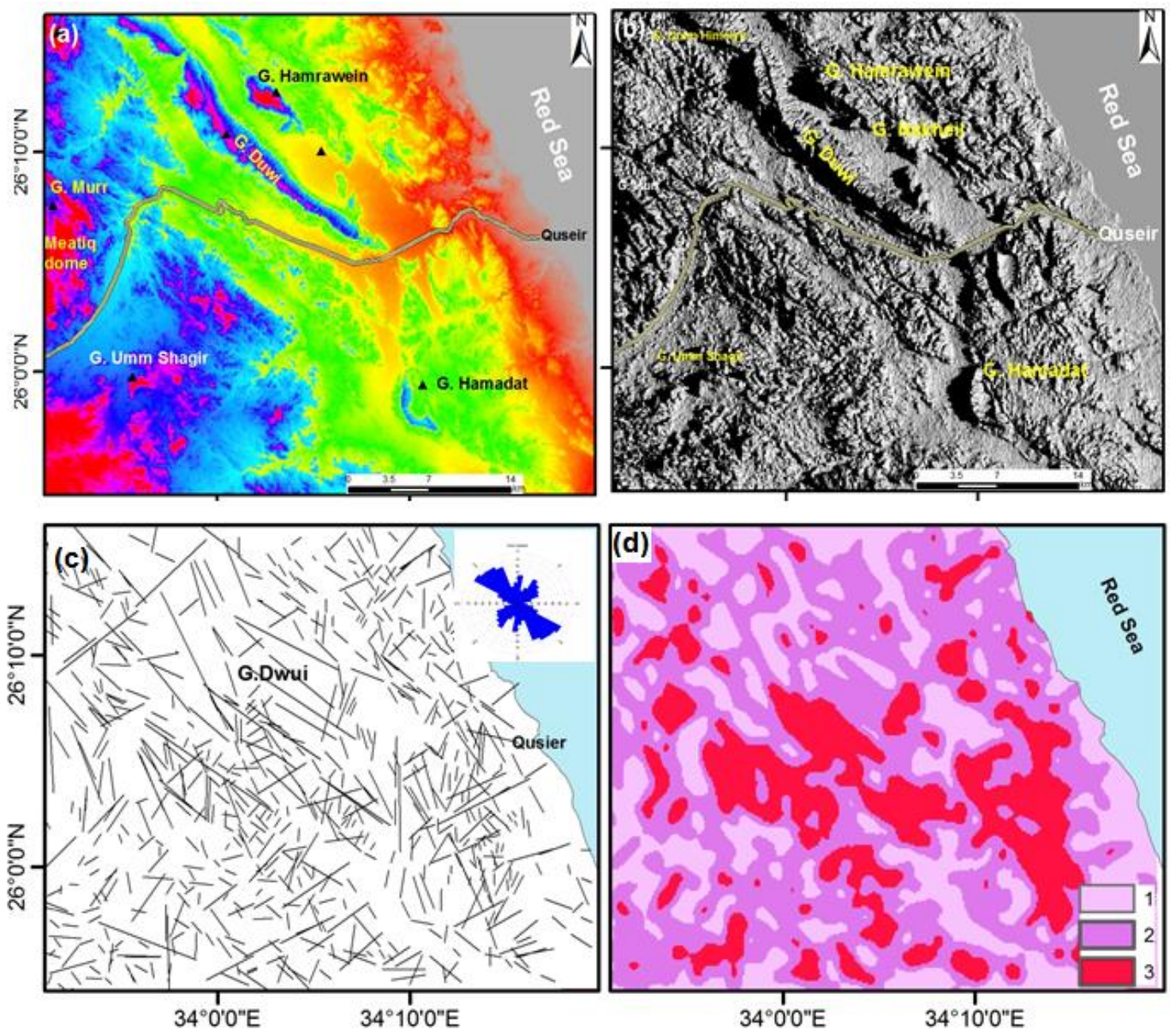

Figure 4. (a) SRTM-DEM m; (b) hill shade relief; (c) lineaments derived from remote sensing data (d) lineament density of remote sensing data

\section{Aeromagnetic data}

\subsection{Aeromagnetic anomalies}

The study area reveals a magnetic anomaly ranging between -181.5 and 33.2 nT. The high magnetic anomalies, which characterized by short wavelengths, are observed in the southeastern, northwestern and western parts. However, the lowest magnetic anomalies (along wavelengths) are located in the southern part of the study area (Figure 5a). These anomalies are characteristic for the areas of the basement rocks outcrops and that covered by sedimentary cover, respectively. The sedimentary cover areas of Gabel Duwi area and its surroundings and the coastal area are manifested with the areas of low magnetic anomalies. The magnetic anomaly map revealed that the study area is structurally controlled and the predominant trends of the anomalies are NW-SE, NE-SW, N-S, and E-W.

The magnetic variation map (Figure 5a) was transformed into reduction to the pole (RTP) grid using the 6 | Mohamed Abdelkareem et al.
2D - FFT (Fast Fourier Transform) filter (Figure 5b). The parameters which used for the transformation include an inclination of 39.5 and declination of 2, representing the mean values.

The resulted RTP map of the study area (Figure 5b) shows the presence of many magnetic zones with maximum amplitude values of about $115 \mathrm{nT}$. They are observed in southeastern and southwestern parts of the study area that associated with a metavolcanics, metasediments, metagabbros and younger granites above G. Umm Shagier, G. Muweilih, G. Umm Khurs and north G. Hamadat. Similar observations are detected in the western part related to metamorphic complexes of G. Umm Baanib and also in the northern part. The magnetic anomalies of this zone are defined by a broad high magnetic anomaly with an elongated to semicircular shape. These anomalies trend in the NE-SW, NW-SE, N-S and E-W directions. On the other hand, the magnetic anomalies with a low amplitude value of $-228.95 \mathrm{nT}$ are observed at the southwestern part of the study area and they

Remote Sensing 
are related to metasediments and Quaternary deposits above G. Umm Hombose. These areas also marked by the elongated shapes that trend in NE-SW and NW-SE directions.

\subsection{Residual magnetic anomalies}

In areas of basement exposures, the aeromagnetic anomalies reflect the magnetic mineral contents of the rock units (Alexander et al., 2015). Magnetic variations in areas of fracture/fault zones represent the favorable sites of mineralization. In the residual map, there are chains of small circular peaks magnetic anomaly closures, associated with volcanic and granitoid intrusions (Figure 5c). Porphyry deposits are often around the intrusive masses (Shahi and Kamkar-Rouhani, 2014). For example, tin (Sn) deposits most likely occur in the outer zone of the granitic body and tin also associated with magnetite mineralization. Therefore, these areas are shown in (Figure 5c) reveals high grade of magnetic intensity. Many magmatic intrusions and quartz veins are involved with the hydrothermal activities. According to Rigol-Sanchez et al. (2003), the high residual magnetic values pointed out zones of plausible ore-bearing buried anomalous bodies. Therefore, zones of elevated magnetic anomalies highlight areas of higher magnetic content. In addition to the aforementioned information, the image clearly highlighted the NE- SW zone that probably intersect and dislocated the NW-SE basin.

\subsection{Euler deconvolution}

The Euler deconvolution method was performed using the RTP grid with structural indexes of (0) and with a moving window of $10 \times 10$ and Euler solution was accepted on the criterion of errors $10 \%$. The resulted map obtained in this case (Figure 5d) shows depth solutions ranges from 0 to $2000 \mathrm{~m}$ and most of these solutions are fall in the range of 0 to $500 \mathrm{~m}$ represented the shallow sources. These causative sources are extended in the NW-SE, NE-SW, and N-S.

\subsection{Lineaments derived from aeromagnetic data}

Subsurface linear structures identified in the study area from regional and residual magnetic maps (Figure 6a and Figure 6b) revealed lineations with trend directions in NW-SE, NE-SW, NNW-SSE, and NNE-SSW, with minor directions in ENE-WSW and WNW-ENE. Lineament density map obtained from sub-surface aeromagnetic data revealed the majority of elongated NW-SE zones and their intersected NE-SW trends (Figure 6b).

The lineaments that were deduced from aeromagnetic data are compiled from RS to produce an integrated lineament map (Figure 7a) which represents the major surface and sub-surface structures (faults/fractures). Analysis of lineament of both RS and AMG data revealing that the NW-SE and NE-SW lineaments are predominant trends in the present study. The extracted lineaments from these data were interpreted to density map (Figure 7b). This map revealed a high density of fracture/fault zones around Umm Had, Duwi area, Wadi Kareim, and in the middle section of the study area. Moreover, the density map reveals a predominant NW-SE trend that intersects by the NE-SW trend.

The detected linear trends have played a major role in controlling the geodynamic evolution of the study area Also it is shown that there are several strike slip faults were detected in NE-SW and NW-SE directions that have sub-surface continuation (Figure 6a, Figure 6b). This explains a probable dislocation of G. Duwi area north of Qift-Quseir Road from its counterpart of the sedimentary succession in the south. Landsat data validated these trends which controlled the rock units and also represent the favorable sites of the hydrothermal solutions.

In order to prepare the lineament map for further combination, we classified it into five classes after assigning weigh factor represented by numeric numbers 1 , 2 , and 3 (Figure $\mathbf{7 b}$ ). The high value represents the higher density and the favorable site of mineral resources. Since several mineral deposits are related to hydrothermal solutions that ascending through fractures/fault zones. Therefore, zones of higher lineament density which related to tectonic/structural deformation of the lithosphere (Alexander et al., 2015) represent a prone area of mineral resources. After converting the lineament density map into a weighted map, we superimposed the existing mines on this map. This (Figure 7b) results revealed a positive correlation between the primary mineral-occurrences such as talc, iron, cassiterite, and $\mathrm{Cu}-\mathrm{Au}-\mathrm{Pb}-\mathrm{Zn}$ mineralizations. 

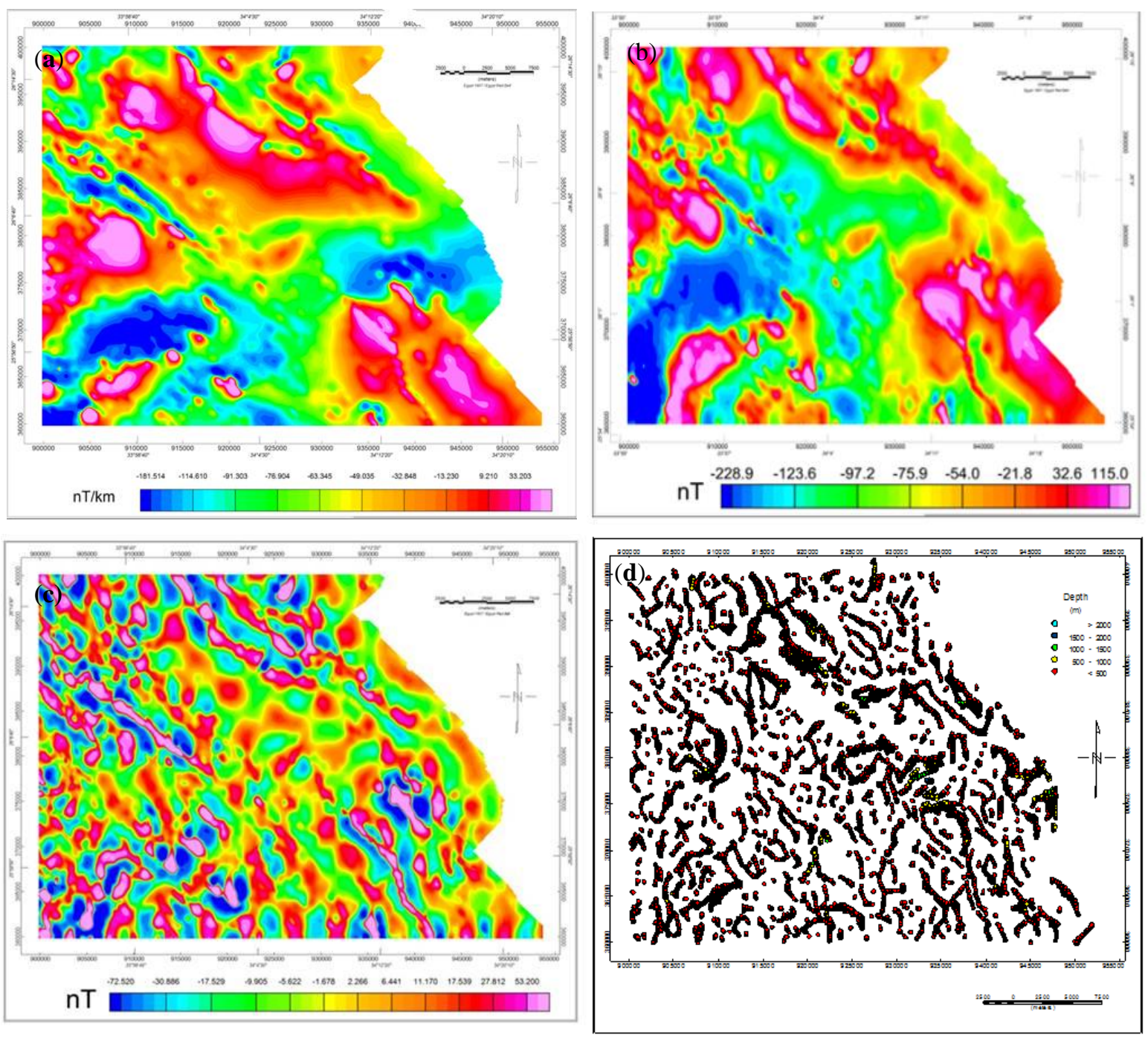

Figure 5. (a): Total magnetic intensity map of the study area; (b): Reduction to the pole map of the study area; (c) Residual magnetic anomaly map; (d) Standard Euler deconvolution applied to RTP magnetic intensity map with structural index $(\mathrm{SI})=0$.

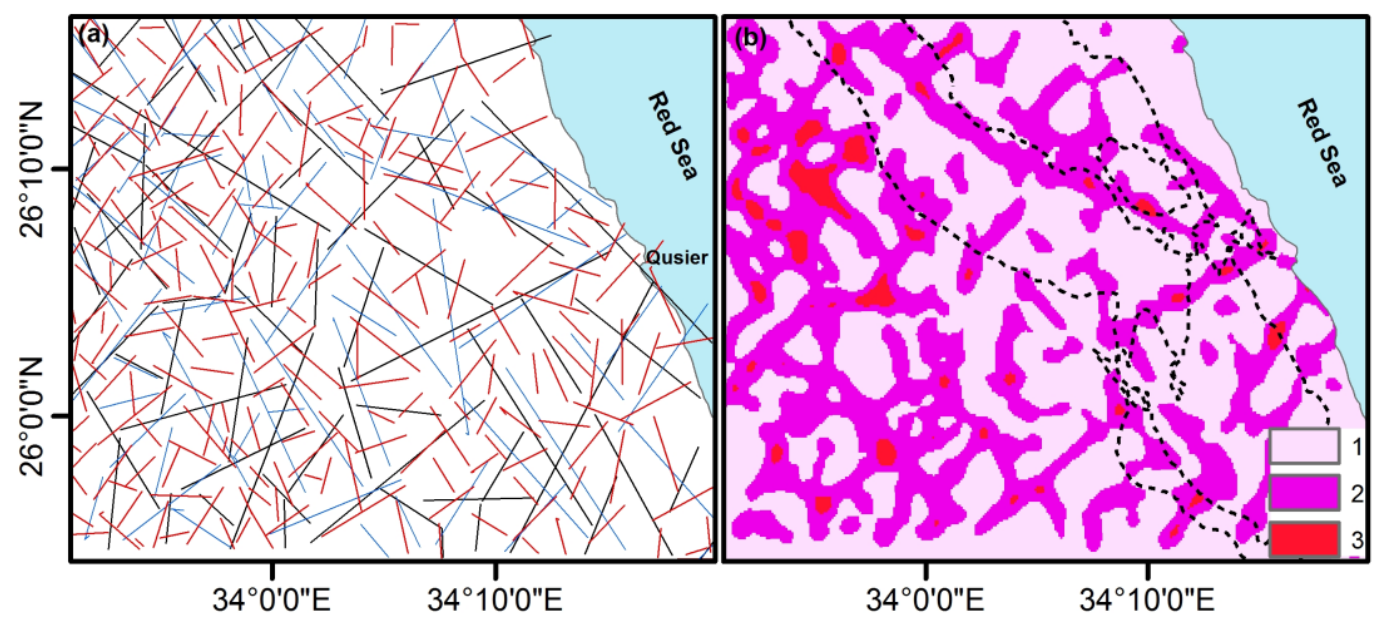

Figure 6. (a) lineaments derived from magnetic anomaly maps; (b) lineament density map from magnetic maps revealing linear anomalies of deep seated structures of regional extent. 


\section{Integrated maps for predicting areas of mineral resources}

The method of combining several data in a geospatial analysis technique is significant in mineral potential mapping (Rigol-Sanehez et al., 2003). To determine the probable area of mineral resources in the form of weighted map, an integrated approach has been adopted for characterizing the areas of mineral occurrences (Woldai et al., 2006). These data were adapted in raster to allow comparing and integrating peer-pixels in the image array. In this section, the lineaments and alternation zones that generated from RS and AMG data are integrated. They are represent the appropriate indicators of mineralization and are effective reconnaissance approach in mineral exploration.

This process of hydrothermal activities commonly occurs along the faults and fracture zones. In addition, radar remote sensing data allowed detecting fracture and fault zones (lineaments). Thus, integration of optical and radar RS data can help in detecting mineral resources associated with hydrothermal solutions. Therefore, when considering the optimal location for a new mineral prospect, there are many factors need to be considered, including, for example, the fracture/fault zones and altera- tion zones.

Applying a spatial dimension of these factors using geographic information system (GIS) could be a useful tool to find the suitable location for new mineral prospect. Find the high lineament density area by applying spatial analysis technique allowed detecting the most area of fracture/fault zones. Such areas represent the favorable sites for mineral occurrences; therefore, we classified the lineament density map into several classes, the highest class represents in red color; however, the lower represents in light magneta (Figure 7b).

The high areas of alteration appear with a red color, followed by magenta, cyan, and yellow colors. In order to achieve the optimal result, we combined the altered areas which obtained from multi-sources and the lineament density map. The results revealed that the most suitable areas predicted by GIS tool are consistent with areas of high alteration and high lineament density. Moreover, these areas displaying good correlation with the well-known area of the existing mines (Figure 8). These combined data from remote sensing including lineaments and alteration zones (Figure 3g, Figure 7b) can be employed in predicting areas of probable mineral resources.

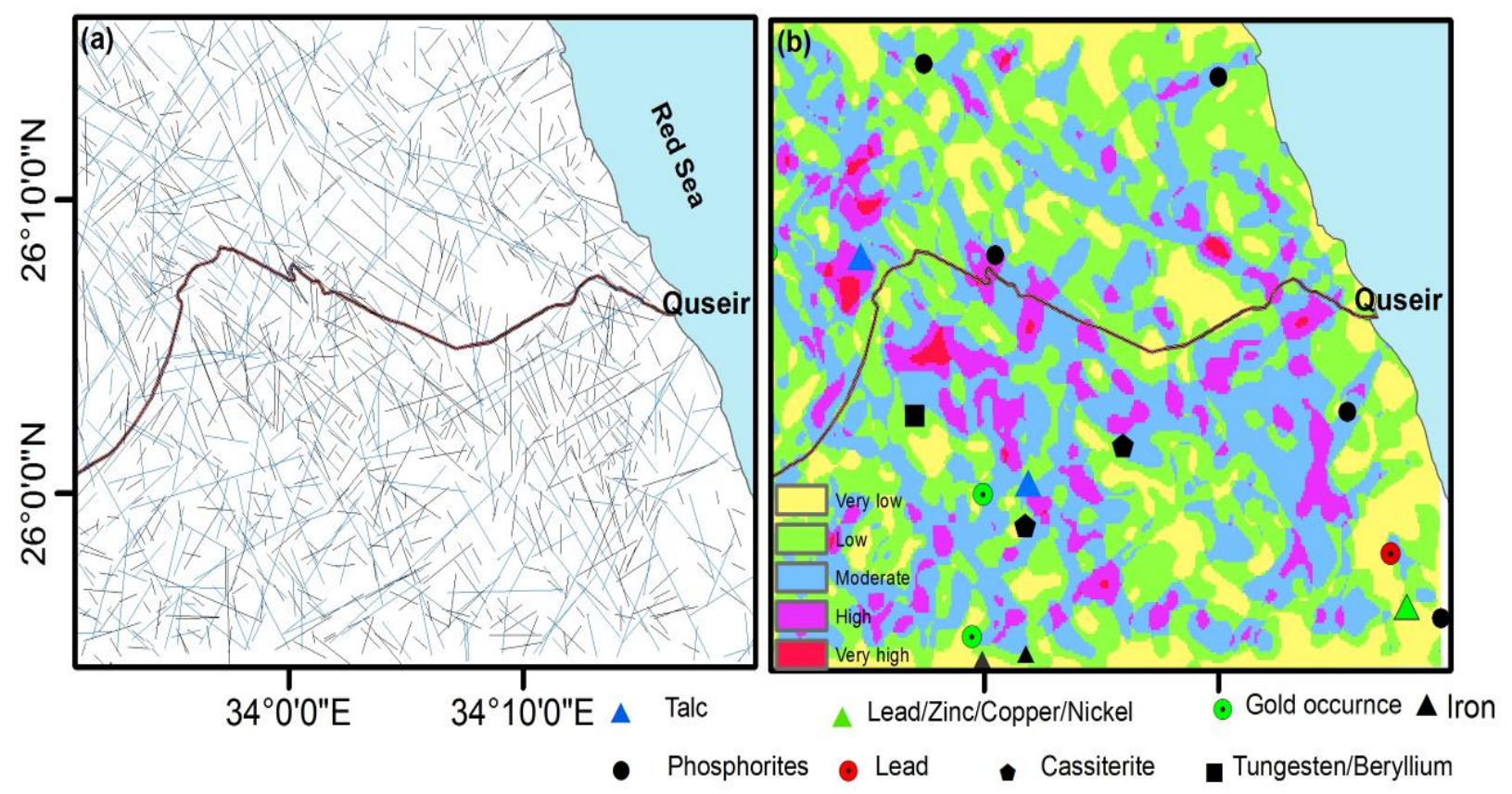

Figure 7. (a) An integrated lineaments from remote sensing (black) and magnetic data (blue); (b) Lineament density map from remote sensing and magnetic data. 


\subsection{Mineral predictive map}

The collected data were digitally superimposed in a GIS and combined using spatial analysis techniques. The final map after combining lineaments (from aeromagnetic data, and remote sensing) magnetic residual anomalies, and HAZs allowed delineating the probable sites of mineral resources. This map was distinguished into five zones include very high, high, moderate, low, and very low areas of mineral occurrences. Overlay the existing sites of mineralization on the final map revealed that talc, cassiterite, gold, and copper/lead mineralization displayed positive correlation with areas of very high to high favorability with areas of very high to high favorability (Figure 8). However, some mineralizations are difficult to be predicted that aren't correlated with lineaments or alteration zones such as phosphorites.

\subsection{Field validation}

In order to validate the extracted lineaments, predicted areas of alteration zones, and verify the mineral potential map, we have used existing mines and conducted field trip in November 2016. Based on field observations, the NW lineaments were predominant over the other trends. Most of these features include fractures/fault zones that are filled by quartz veins, sills, and dykes mostly of felsic composition (Figure 9). Five field stops were checked, most of these sites revealed minerals involved with hydrothermal activities such as talc, gold, and areas rich in muscovite and talc-schist. However,

\section{Conclusions}

The study area is located west of the Quseir city, Red Sea, Egypt. Integration of RS and AMG data allowed detecting structural discontinuity and HAZs in the present study area. Image transformation techniques including band ratios and PCA were performed to Landsat OLI to reveal area of HAZs. The resulting image was discriminated into five zones characterizing the degree of the alteration. SRTM data was used to extract lineaments. Subsurface lineaments were delineated using the AMG some areas were related to altered metavolcanics and associated metapyroclastics in the right hand of Qift-Quseir road. Some trends that were extracted from the aforementioned data are clearly observed in the field e.g. strike slip faults along the major trends of NW-SE, and some of them allowd formation of the sedimentery basins. These trends may control the rock units and mineralizations. They are mostly shears and fractures that vary from centimeters to meters in width, mostly occupied by quartz veins. Foliations and alterations are common in these rocks that represented by multi-deformation.

Evidence of alteration processes include multi-colored rocks, silicification, iron-oxides, and carbonization that varies in thickness. The host rocks of the metavolcanics were sheared and altered to talc-carbonates. It pervasively altered to carbonates and micaceous minerals. Field investigations revealed that the tested areas characterized by alteration zones enriched in talc, calcite and secondary amphiboles. It is found that the HAZs are more consistent with the lineaments extracted from magnetic intensity map (Figure 8 and Figure 9). This indicated that alteration zones usually connected to deep lineaments. This integration shows that the approaches of RS and AMG maps are effective techniques for exploring iron- and $\mathrm{OH}$ bearing minerals. Moreover, they presented a positive relationship between the primary mineral occurrences and areas of high lineaments and alteration zones.

data using several tools. In order to maximize area of probable mineral resources, HAZs and lineament density were combined to prepare mineral prospect map. Field validation allowed verifying the prepared map and revealed several mineralized zones including talc, gold mines and quartz veins-bearing hematite.

\section{Acknowledgment}

We thank the World Academy of Science (TWAS) for the support. 


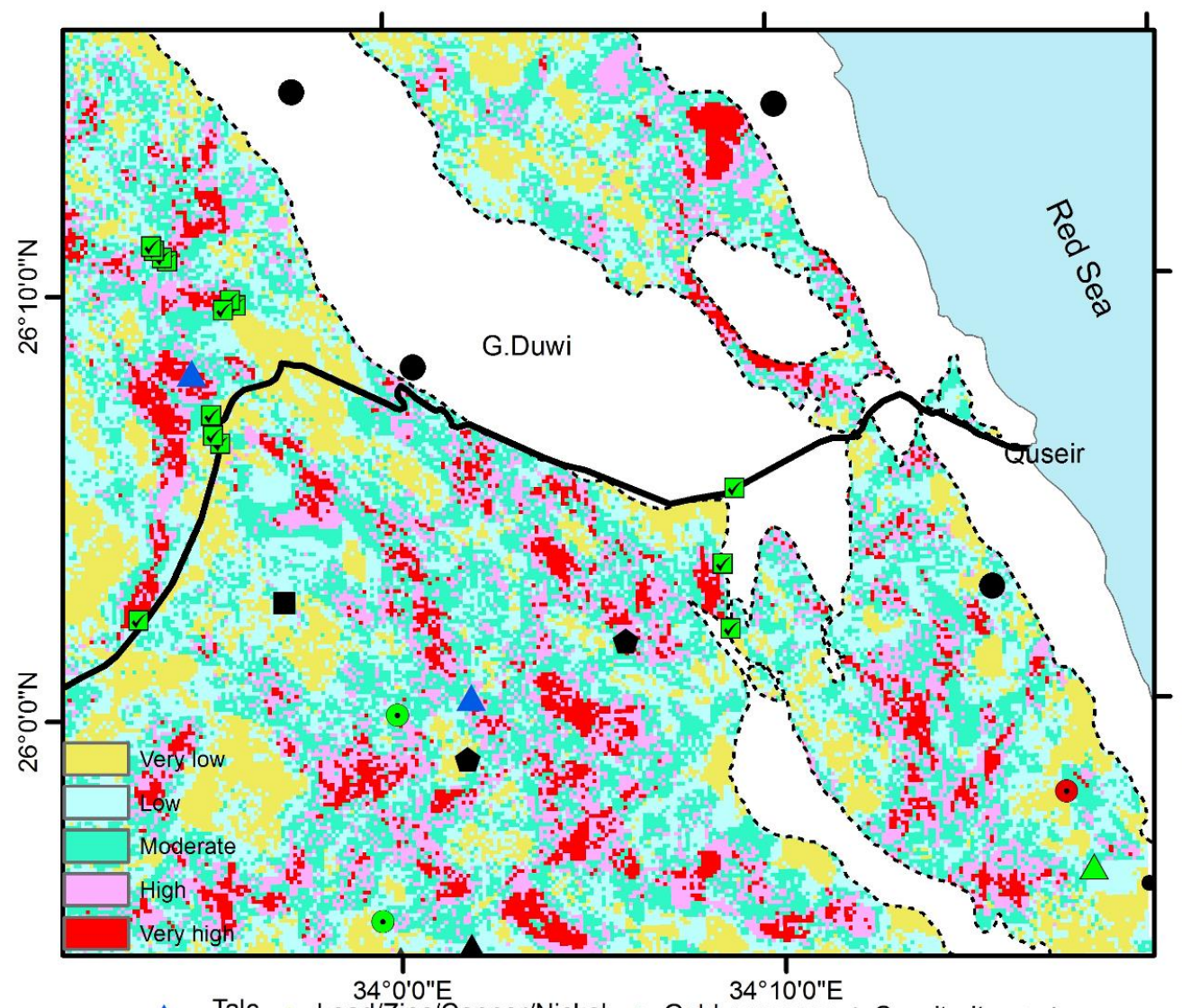

- Talc $\triangle$ Lead/Zinc/Copper/Nickel $\odot$ Gold occurnce $\bullet$ Cassiterite $\Delta$ Iron

- Phosphorites $\odot$ Lead $\square$ Tungesten/Beryllium $\square$ Field validation

Figure 8. Mineral predictive map obtained by combining alteration zone and lineaments.
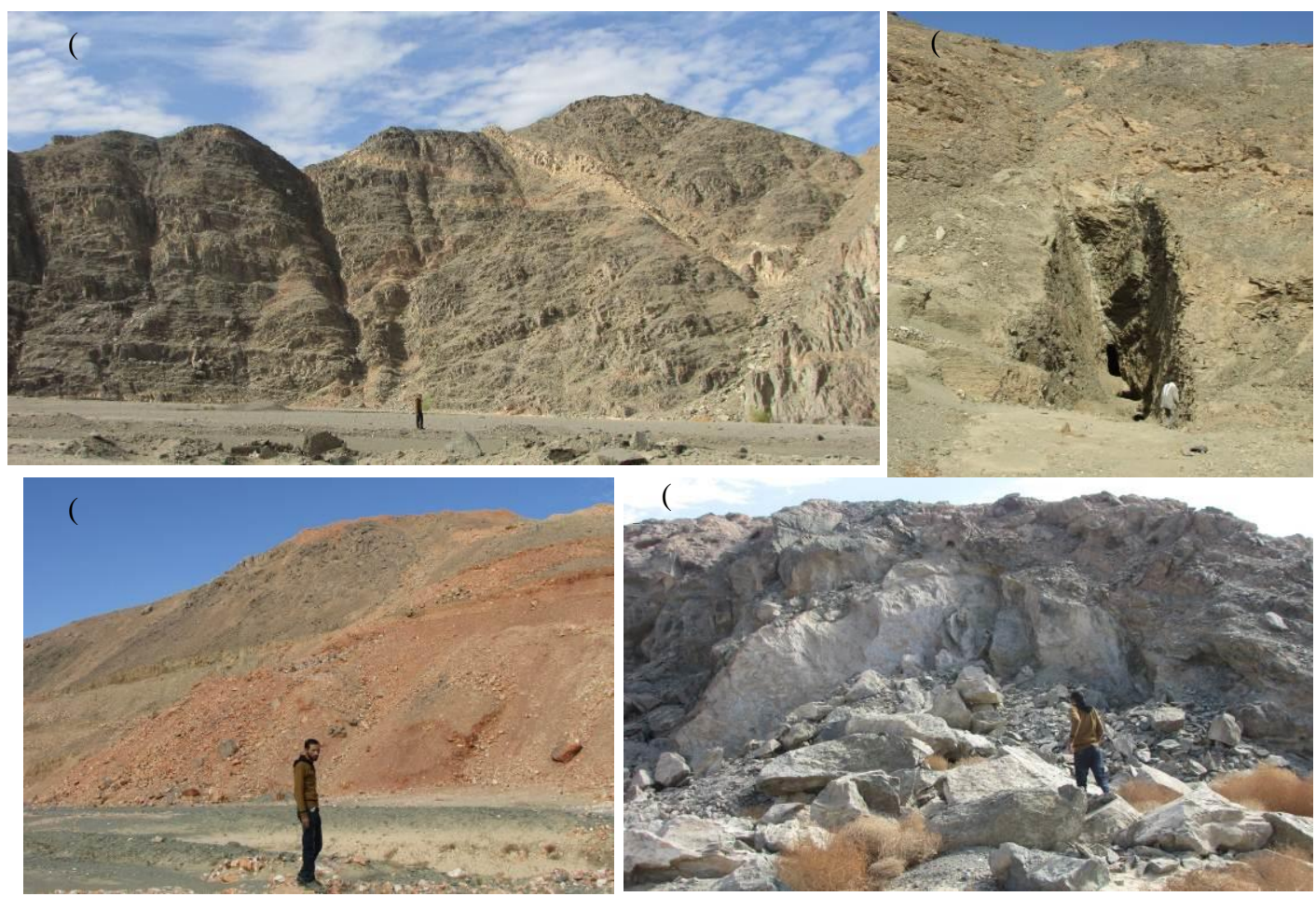

Figure 9. Field photographs (a) NW-SE joints, swarms of dykes and faults that cutting the metavolcanic rocks, (b) NW-SE quartz vein and alteration zones in gold mineralization, (c) site of hematite and quartz veins, (d) talc associated with serpentinites. 


\section{References}

1. Abdelkareem, M., El-Baz, F. (2015): Mode of formation of the Nile Gorge in northern Egypt: a study by DEM-SRTM data and GIS analysis. Geological Journal, Wiley.Vol. 51: 760-778

2. Abdelkareem, M., El-Baz F. (2017): "Characterizing hydrothermal alteration zones in Hamama area in the central Eastern Desert of Egypt by remotely sensed data." Journal of Geocarto International, In Press.

3. Abdelkareem, M., Kamal El-Din, Osman I. (2018): An integrated approach for mapping mineral resources in the Eastern Desert of Egypt. International Journal of Applied Earth Observation and Geoinformation, 73, 682-696.

4. Abdelsalam, M.G., Stern, R.J., Berhane, W.G. (2000): Mapping gossans in arid regions with Landsat TM and SIR-C images: the Beddaho Alteration Zone in northern Eritrea. Journal of African EarthSciences, 30(4): 903-916 pp.

5. Ahmed A, Abdelkareem M, Asran M. Asran, Tawfig M. Mahran. 2017. Geomorphic and lithologic characteristics of Wadi Feiran basin, Southern Sinai, Egypt, using remote sensing and field investigations. Earth System Science Journal, 126:85, 1-25.

6. Alexander, Io., Samuel, O.O., Esther, C.M., Theophillus, T.E., Kingsley, C.I., Kingsley, C.N., (2015): Integrating Landsat-ETM and Aeromagnetic data for enhanced structural interpretation over Naragwata area, North - Central Nigeria. International Journal for Science and Engineering Research, 6 (9), 2229-5518.

7. Amuda OS., Adebisi S., Jimoda L., Alade A. (2014): Challenges and Possible Panacea to the Municipal Solid Wastes Management in Nigeria. J. Sust. Dev. Studies. 6 (1):64-70.

8. Cappaccioni, B., Vaselli, O., Moretti, E., Tassi, F., Franchi, R. (2003): The Origin of thermal water from the eastern flank of the Dead Rift Valley. Terra Nova 15 (3),145.

9. Conoco (1987): Geological Map of Egypt, Scale 1:500,000, Sheet NG36NW Quseir-NG36NW Asyut, Egypt. The Egyptian General Petroleum Corporation, Cairo, Egypt.

10. Edgardo, G., James, Hurtak, J. (1992): Laser Remote Sensing of Forest and Crops in Genetic-rich Tropical, vol. XXIX. International Archives of Photogrammetry and Remote Sensing. ISPRS, 7 pages.

11. El-Etr, H.A., Yousef, M.S.M., Dardir, A.A. (1979): Utilization of Landsat images and conventional aerial photographs in the delineation of some aspects of the geology of the Central Eastern Desert, Egypt, Annals of Geological Survey of Egypt, ix, 136162.

12. El Khidir, S.O., Babikir, I.A. (2013): Digital image processing and geospatial analysis of landsat 7 ETM+ for mineral exploration, Abidiya area, North Sudan. International Journal of Geomatics and Geosciences, 3, (3), 645-658.
13. Eldosouky, A. M., Abdelkareem, M., Elkhateeb, S. O. (2017): Integration of remote sensing and aeromagnetic data for mapping structural features and hydrothermal alteration zones in Wadi Allaqi area, South Eastern Desert of Egypt. Journal of African Earth Sciences 130: 28-37.

14. El-Rakaiby, M.L. (1995): the use of enhanced Landsat-TM image in the characterization of uraniferous granite rocks in the central Eastern Desert, Egypt. International Journal of Remote sensing. 16 (6), 1063-1074.

15. Farghaly, A.M.A. (1999): Structural framework of the Central-Eastern Desert of Egypt, using remote sensing techniques and ground data. Ph.D. Thesis, South Valley University. Sohag.

16. Gad, S., Kusky, T. (2006): Lithological mapping in the Eastern Desert of Egypt, the Barramiya area, using Landsat thematic mapper (TM), Journal of African Earth Sciences. (in press).

17. Gass, I. G. (1977): The evolution of the Pan-African crystalline basement inNE Africa and Saudi Arabia. Journal of the Geological Society of London., 134: 129-138.

18. Ghebreab, W. (1998): Tectonics of the Red Sea region reassessed. Earth Science Rev. 45, 1-44.

19. Goetz, A.F.H., Rock, B.N., Rowan, L.C. (1983): Remote sensing for exploration, an overview. Economic Geology., 78, 573-590.

20. Hsu Shu-Kun (2002). Imaging magnetic sources using Euler's equation. Geophysical prospecting, 50, pp 15-25.

21. Kamal El-Din, G., Abdelkareem, M., 2018. Integration of remote sensing, geochemical and field data in the Qena-Safaga shear zone: Implications for structural evolution of the Eastern Desert, Egypt. Journal of African Earth Sciences 141, 179-193.

22. Kröner, A. (1985): Ophiolites and the evolution of tectonic boundaries in theLate Proterozoic Arabian-Nubian Shield of Northeastern Africa and Arabia Precambrian Research, 27(1-3), 277-300.

23. Madani, A., Abdel Rahman, E. M., Fawzy, K. M., Emam, A. (2003): Mapping of the hydrothermal alteration zones at Haimur Gold Mine Area, South Eastern Desert, Egypt using remote sensing techniques; The Egyptian Journal Remote Sensing Space Science, 6: 47-60.

24. O'Connor, E.A., McDonald, A.J.W. (1988): Application of remote sensing for geological mapping in Eastern Desert, Egypt. Proceeding of IGARSS' 88 symposium, Edimburg, Scotland, 631-632.

25. Poormirzaee, R., Oskouei, M.M. (2010): Use of spectral analysis for detection of alterations in ETM data, Yazd, Iran. Applied Geomatics Journal, 4, 147-154.

26. Ramadan, T.M., Abdelsalam, M.G., Stern, R.J. (2001): Mapping gold-bearing massive sulfide deposits in the neoproterozoic Allaqi Suture, Southeast Egypt with Landsat TM and SIR-C/X SAR images. Photogrammet. Eng. Remote Sens. 67 (4), 491e497. 
27. Ramadan, E., Feng, X.Z., Cheng, Z. (2004): Satellite remote sensing for urban growth assessment in Shaoxing City, Zhejiang Province. Journal of Zhejiang University Science, 5(9), 1095-1101.

28. Ramadan, T.M., Kontny, A. (2004): Mineralogical and structuralcharacterization of alteration zones detected by orbital remote sensingat Shalate in District, South Eastern Desert, Egypt. Journal of African Earth Sciences, 40, 89-99.

29. Ramadan, T.M., Sultan, S.A. (2004): Integration of Remote Sensing, Geological and Geophysical Data for the Identification of Massive Sulphide Zones at Wadi Allaqi Area, South Eastern Desert, Egypt, vol. 18. M.E.R.C. Ain Shams Univ, pp. 165e174. Earth Sci. Ser.

30. Reid, A. B.; Allsop, J. M.; Granser, H.; Millett, A. J., Somerton, I.W. (1990): Magnetic interpretation in three dimensions using Euler deconvolution, Geophysics, 55, 80-91.

31. Rigol-Sanchez, J.P., Chica-Olma, M., Abarca-Hernandez, F. (2003): Artificial neutral networks as a tool for mineral potential mapping with GIS. International Journal of Remote Sensing, 24 (5), 1151-1156.

32. Sabins, F. (1997): Remote Sensing Principles and Interpretation. Third ed., W.H. Freeman Company, 494 P.

33. Sabins, F. (1999): Remote Sensing for Mineral Exploration. Ore Geology Review, 14, 157-183.

34. Said, R. (1962): Tectonic framework of Egypt and its influence on distribution of Foraminifera. AAPG Bull, 45, 198- 218.

35. Said, R. (ed.) (1990): The Geology of Egypt, x
+ 734 pp. Rotterdam, Brookfield: A. A. Balkema.

36. Segal, D. B. (1983): Use of Landsat Multispectral Scanner Data for Definition of Limonitic Exposures in Heavily Vegetated Areas. Econ.Geol., EL Paso, Texas, 78, 711-722.

37. Shahi, H., Kamkar-Rouhani, A. (2014): A GIS-based weights - of - evidence model for mineral potential mapping of hydrothermal gold deposits in Torbat-e-Heydarieh area.

Journal of Mining \& Environment, 5 (2), 79-89.

38. Sultan, M., Arvidson, R.E., Sturchio, N.C. (1986): Mapping of serpentinites in the Eastern Desert of Egypt by using Landsat thematic mapper data. Journal of Geology, 14(12): 995-999.

39. Sultan, M., Arvidson, R.E., Sturchio, N.C., Guinness, E.A. (1987): Lithologic mapping in arid regions with Landsat thematic mapper data: Meatiq Dome, Egypt. Geologic Society Am. Bull 99(6):748-762.

40. Sultan M, Arvidson R.E., Duncan, I.J., Stern, R.J., El-Kaliouby, B.E. (1988): Extension of the Najd shear system from Saudi Arabia to the Central Eastern Desert of Egypt based on integrated field and Landsat observations. Tectonics 7, 1291-1306.

41. Thompson, D. T. (1982): EULDPH-A new technique for making computer-assisteddepth estimates from magnetic data: Geophysics, 47, 31-37.

42. Woldai, T., Pistocchi, A., Master, M. (2006): Validation and sensitivity analysis of a mineral potential model using favourability functions applied GIS, Volume 2, No. 1, Monash University, press 19 p. 